\title{
Right Ventricular Dysfunction in Chronic Lung Disease
}

\author{
Todd M. Kolb, MD, PhDa and Paul M. Hassoun, MD ${ }^{b, c}$ \\ aPost-Doctoral Fellow, Division of Pulmonary and Critical Care Medicine, Johns Hopkins \\ University, Baltimore, Maryland bProfessor of Medicine, Division of Pulmonary and Critical Care \\ Medicine, Johns Hopkins University 'Director, Pulmonary Hypertension Program, Johns Hopkins \\ University, Baltimore, Maryland
}

\begin{abstract}
Right ventricular dysfunction arises in chronic lung disease when chronic hypoxemia and disruption of pulmonary vascular beds contribute to increase ventricular afterload, and is generally defined by hypertrophy with preserved myocardial contractility and cardiac output. Although the exact prevalence is unknown, right ventricular hypertrophy appears to be a common complication of chronic lung disease, and more frequently complicates advanced lung disease. Right ventricular failure is rare, except during acute exacerbations of chronic lung disease or when multiple comorbidities are present. Treatment is targeted at correcting hypoxia and improving pulmonary gas exchange and mechanics. There are presently no convincing data to support the use of pulmonary hypertension-specific therapies in patients with right ventricular dysfunction secondary to chronic lung disease.
\end{abstract}

\section{Keywords}

right ventricle; pulmonary hypertension; cor pulmonale; chronic lung disease

\section{Introduction: Nature of the Problem}

Nearly 200 years ago, Laennec described the relationship between chronic pulmonary disease and right ventricular (RV) dysfunction: "All diseases which give rise to severe and long-continued dyspnœa produced, almost necessarily, hypertrophia or dilatation of the heart, through the constant efforts the organ is called on to perform, in order to propel the blood into the lungs against the resistance opposed to it by the cause of the dyspnœa"1. Our understanding of cardio-pulmonary pathophysiology has increased exponentially since that publication, though Laennec's basic observation concisely described the essence of RV dysfunction in chronic lung disease. Structural changes of the lung parenchyma and functional abnormalities in gas exchange lead to pulmonary hypertension $(\mathrm{PH})$, with

\footnotetext{
(c) 2012 Elsevier Inc. All rights reserved.

${ }^{a}$ Coauthor address: Todd M. Kolb, MD, PhD Johns Hopkins Division of Pulmonary and Critical Care Medicine 1830 E. Monument Street, $5^{\text {th }}$ Floor Baltimore, Maryland 21205 410-955-3467 Fax: 410-955-0036 tkolb1 @jhmi.edu. ${ }^{b, c}$ Corresponding author for proof and reprints: Paul M. Hassoun, MD Johns Hopkins Division of Pulmonary and Critical Care Medicine1830 E. Monument Street, $5^{\text {th }}$ Floor Baltimore, Maryland 21205 410-955-3467 Fax: 410-955-0036 phassou1@jhmi.edu.

Publisher's Disclaimer: This is a PDF file of an unedited manuscript that has been accepted for publication. As a service to our customers we are providing this early version of the manuscript. The manuscript will undergo copyediting, typesetting, and review of the resulting proof before it is published in its final citable form. Please note that during the production process errors may be discovered which could affect the content, and all legal disclaimers that apply to the journal pertain.

The authors have nothing to disclose.
} 
subsequent RV remodeling and hypertrophy. The term "cor pulmonale" had previously been used to describe this relationship, though the importance of $\mathrm{PH}$ was not emphasized ${ }^{2}$. More recently, several disorders associated with chronic lung disease or hypoxia have been grouped together in the classification of $\mathrm{PH}^{3}$. In general, these disorders are characterized by mild $\mathrm{PH}$, and RV dysfunction is characterized by hypertrophy with preserved cardiac function. However, RV failure can occur during disease exacerbations or when multiple comorbidities are present, and the development of $\mathrm{PH}$ increases mortality in many chronic pulmonary conditions.

The current review will focus on World Health Organization Group 3 disorders (Box 2), with primary attention to chronic obstructive pulmonary disease (COPD), interstitial lung disease (ILD), and sleep disordered breathing (SDB), as these account for the bulk of cases. COPD is estimated to account for approximately $80 \%$ of Group 3 disease $e^{4,5}$. It should be noted that other diseases, including sarcoidosis, pulmonary Langerhans cell histiocytosis, and scleroderma-associated lung disease, can produce both parenchymal lung disease and pulmonary hypertension, but given their complex effects on the pulmonary vasculature, are not grouped with other chronic lung diseases in the most recent PH classification ${ }^{3}$. The key points opf this article are summarized in Box 1.

\section{Prevalence of $\mathrm{PH}$ in chronic lung disease}

The prevalence of PH in chronic lung disease has been difficult to quantify given limited population-based hemodynamic data and variability in the definition used to identify PH in these patients. Chronic lung disease appears to be a common co-morbidity in patients with $\mathrm{PH}$, present in $25.9 \%$ of all patients who died from pulmonary hypertension in the United States between 2000 and $2002^{6}$. Prevalence estimates for PH in COPD range from 30-70\% ${ }^{7}$, with $\mathrm{PH}$ being more common in patients with advanced disease. In one trial of patients with severe emphysema evaluated for lung volume reduction surgery, $61.4 \%$ of patients had a mean pulmonary artery (PA) pressure greater than $20 \mathrm{~mm} \mathrm{Hg}^{8}$. As this value represents the upper limit of normal resting mean PA pressure ${ }^{9}$, most investigators have used this value to define $\mathrm{PH}$ in chronic lung disease, despite the higher mean PA pressure required to define pulmonary arterial hypertension. The prevalence of $\mathrm{PH}$ and $\mathrm{RV}$ dysfunction in other obstructive lung diseases, including asthma, cystic fibrosis, bronchiolitis obliterans, and bronchiectasis is less clear. Prevalence estimates for ILD-associated PH are even more variable $(8-84 \%)$, probably due to the heterogeneous nature of these disorders ${ }^{10}$. Pulmonary hypertension prevalence increases with ILD severity, from $8.1 \%$ in idiopathic pulmonary fibrosis (IPF) patients at initial evaluation ${ }^{11}$ to $30-40 \%$ in IPF patients at the time of transplant evaluation or referral to tertiary care ${ }^{12,13}$. Obstructive sleep apnea (OSA) has been associated with $\mathrm{PH}$ prevalence estimates of $20-40 \%{ }^{14}$, though other co-morbidities frequently confound the diagnosis. A single study estimated $\mathrm{PH}$ prevalence in isolated OSA, with all other restrictive and obstructive lung disease excluded, to be $9 \%$, while the prevalence of $\mathrm{PH}$ in patients with obesity hypoventilation syndrome (OHS) was nearly $58 \% 15$.

\section{Pathophysiology}

\section{Effects of chronic pulmonary disease on right heart structure and function}

Hypertrophy of the RV with preserved systolic function is the predominant effect of chronic pulmonary disease. Chronic pulmonary disease results in relatively slow increases in PA pressure (about $3 \mathrm{~mm} \mathrm{Hg} / \mathrm{year}^{16}$ ), allowing time for adequate compensation. The normally thin-walled, compliant RV is hypertrophied to mitigate intraluminal pressure increases, and ultimately minimizes wall stress. Increased RV thickness is accompanied by hypertrophy of 
individual myocytes, remodeling of the myocardial extracellular matrix, alterations in glucose metabolism, and in some models, compensatory increases in capillary density ${ }^{17-19}$.

Concentric RV hypertrophy can precede resting hypoxia in stable COPD patients ${ }^{20}$, and has been demonstrated at autopsy in $76 \%$ of patients with advanced COPD ${ }^{21}$. RV hypertrophy was estimated to be present in $50 \%$ of patients with restrictive lung disease ${ }^{22}$. In OSA, one study showed that $71 \%$ of patients had RV hypertrophy by echocardiography ${ }^{23}$. However, it remains unclear whether RV hypertrophy results from isolated OSA or other co-morbidities. While RV wall thickness was increased in subjects with SDB in the Framingham $\operatorname{cohort}^{24}$, a more recent study of OSA patients without pulmonary disease or evidence of LV dysfunction showed no increase in RV wall thickness ${ }^{25}$.

Despite these changes in RV structure, myocardial systolic function is generally preserved in $\mathrm{PH}$ associated with chronic lung disease. Although prior studies have demonstrated that slight reductions in RV ejection fraction occur commonly in chronic lung disease ${ }^{26}$, the dependence of ejection fraction on ventricular pre-load, after-load, and myocardial contractility makes this observation difficult to interpret. Intrinsic myocardial contractility appears to be preserved in COPD patients, as demonstrated by the normal RV end-systolic pressure-volume relationship measured at rest and with exercise ${ }^{27,28}$. RV diastolic function may be impaired in chronic lung disease patients with $\mathrm{PH}$, as demonstrated by the direct associations between $\mathrm{PH}$ and reduced early to late ventricular filling velocity ratio (E/A ratio) and prolonged myocardial relaxation time in COPD patients ${ }^{29}$. Impaired RV diastolic function can also be demonstrated in healthy individuals exposed to acute hypoxia ${ }^{30}$.

\section{Effects of chronic pulmonary disease on RV afterload}

Increased pulmonary vascular resistance (PVR) is the sine qua non of RV dysfunction in chronic pulmonary disease. Chronic hypoxemia and disruption of pulmonary vascular beds through parenchymal loss and fibrosis are the key mechanisms through which chronic lung disease increases PVR.

Alveolar hypoxia induces rapid vasoconstriction of small, precapillary pulmonary arteries to preserve the ventilation to perfusion $(\mathrm{V} / \mathrm{Q})$ ratio and minimize effects on arterial oxygen saturation. The mechanisms of hypoxic pulmonary vasoconstriction are reviewed elsewhere $^{31}$, and involve alterations in potassium and calcium flux in smooth muscle cells, resulting in contraction and increased vascular tone. Pulmonary vasoconstriction can be further exacerbated by hypercapnia and acidemia in $\mathrm{COPD}^{32}$ or by increased sympathetic activity in $\mathrm{OSA}^{14}$. Supplemental oxygen administration does not fully reverse the increased PA pressure observed in COPD patients ${ }^{33}$, however, and correlations between PA pressure and systemic oxygenation have not been robust ${ }^{34}$. This may reflect individual differences in the capacity for hypoxic pulmonary vasoconstriction and/or differences in pulmonary vascular remodeling in response to chronic hypoxia. Chronic hypoxia results in remodeling of the pulmonary vasculature, characterized by neo-muscularization of arterioles, medial hypertrophy of small muscular arteries, and intimal thickening and fibroelastosis ${ }^{35}$.

Systemic hypoxemia arises in chronic lung disease through diverse mechanisms. COPD is a chronic inflammatory disorder of small airways that leads to airflow limitation, impaired gas exchange, and parenchymal loss in the case of emphysema. Hypoxemia results from impaired V/Q matching, and is compounded by the loss of alveolar surface area for diffusion in emphysema. Interstitial lung diseases represent a more heterogeneous group of disorders, characterized by inflammatory or fibrotic destruction of lung parenchyma, generally at the level of the alveolar interstitium. These changes may be associated with autoimmune disease, exposure to cigarette smoke and other respiratory irritants, granulomatous diseases, or may be idiopathic. Interstitial changes result in impaired diffusing capacity, which may be 
exacerbated by poor V/Q matching in some patients. In OSA, hypoxia results from hypoventilation during obstructive episodes, and is by definition intermittent. However, in patients with OHS or an overlap syndrome of COPD and OSA, diurnal hypoxemia may be present. At altitude, pulmonary vascular remodeling induced by chronic alveolar hypoxia can be exacerbated by hypoventilation, resulting in chronic mountain sickness, which is frequently associated with $\mathrm{PH}$ and right heart dysfunction ${ }^{36}$.

Another common factor in the increased PVR associated with chronic lung disease is disruption of pulmonary capillary beds. In COPD, loss of alveolated lung tissue, as occurs in emphysema, may result in loss of pulmonary capillary beds. This is supported by the negative correlation observed between diffusing capacity for carbon monoxide $\left(\mathrm{D}_{\mathrm{L}} \mathrm{CO}\right)$ and mean PA pressure in patients with severe COPD ${ }^{37}$. Mechanical compression of extraalveolar vessels by lung hyperinflation had previously been assumed to contribute to PVR, though recent evidence does not support this hypothesis ${ }^{38}$. In ILD, interstitial fibrosis and inflammatory infiltrates may promote loss of pulmonary vascular beds and compression of small vessels. Vessel ablation is common within fibroblastic foci and areas of "honeycombing" ${ }^{39}$. Pulmonary vessel capacitance may also be reduced by nearby fibrosis ${ }^{39}$ or by compensatory proliferation of abnormal capillaries lacking a normal elastin layer ${ }^{40}$. Finally, thromboembolic lesions can further impede pulmonary vascular flow, and frequently complicate chronic lung diseases like COPD ${ }^{41,42}$, sarcoidosis ${ }^{43}$, and IPF ${ }^{44}$.

\section{Effects of chronic pulmonary disease on cardiac mechanics}

Chronic pulmonary disease may alter right and left ventricular function by changing intrathoracic pressure. Lung hyperinflation may increase right atrial pressure, leading to reduced venous return and subsequent reductions in RV pre-load ${ }^{45}$. In COPD patients, hyperinflation has been directly correlated with reduced atrial chamber size, global RV dysfunction, and reduced LV filling ${ }^{46}$. In addition, highly negative pleural pressures may be necessary to facilitate ventilation in COPD or during episodes of airways obstruction in OSA. These highly negative pleural pressures reduce intrathoracic pressure and increase LV wall stress during ejection ${ }^{47}$, potentially resulting in left atrial hypertension and increased RV afterload.

\section{Clinical Evaluation}

\section{Physical Examination}

Distinguishing chronic lung disease from associated PH and RV dysfunction can be difficult. Increased exertional dyspnea may arise from new RV dysfunction or progression of the underlying parenchymal lung disease. Symptoms associated with advanced RV dysfunction (leg edema, ascites) may not be present, or may develop independent of RV dysfunction. In COPD, peripheral edema can develop as a consequence of chronic hypercapnia and renal vasoconstriction with activation of the renin-angiotensin-aldosterone system $^{48}$. Peripheral edema is not a common occurrence in ILD patients with equivalent levels hypoxemia, and is rare in COPD patients without hypercapnea ${ }^{48}$.

Physical signs may also be of limited value in the evaluation of chronic lung diseaseassociated PH and RV dysfunction. Classical signs of RV dysfunction, including a precordial heave, accentuated pulmonic component of S2, murmur of tricuspid regurgitation, or a right sided gallop may not be present in mild disease. Additionally, auscultatory findings may be limited by chest over inflation (in COPD) and the abnormal pulmonary examination of most parenchymal lung disease patients. 


\section{Non-Invasive Evaluation}

Most non-invasive diagnostic modalities lack sufficient sensitivity to identify new RV dysfunction in parenchymal lung disease. Electrocardiogram findings associated with RV dysfunction include a rightward $\mathrm{P}$-wave axis, $\mathrm{S}_{1} \mathrm{~S}_{2} \mathrm{~S}_{3}$ pattern, $\mathrm{S}_{1} \mathrm{Q}_{3}$ pattern, $\mathrm{RV}$ hypertrophy, and right bundle branch block ${ }^{10}$. ECG alone, however, is insensitive for diagnosis of RV dysfunction. In one study of COPD patients with PH, abnormal ECG findings had a sensitivity of only $51 \% 49$.

Plain chest radiography findings associated with $\mathrm{PH}$ and RV remodeling may include enlarged central pulmonary arteries and loss of the retrosternal air space. In patients with COPD, these radiographic abnormalities had a sensitivity of $46 \%$ and specificity of $63 \%$ in detecting $\mathrm{PH}^{49}$. However, on chest $\mathrm{CT}$, enlargement of the main pulmonary artery to a diameter of $29 \mathrm{~mm}$ or greater was associated with a high sensitivity (84\%), specificity $(75 \%)$, and positive predictive value $(95 \%)$ in a heterogeneous group of patients with chronic lung disease ${ }^{50}$. However, CT findings may be less reliable in patients with IPF $^{51}$.

Pulmonary function testing is necessary for initial diagnosis of most chronic lung diseases that cause RV dysfunction, and provides objective evidence of disease progression or stability. Isolated reductions in $\mathrm{D}_{\mathrm{L}} \mathrm{CO}$ have been associated with PH in IPF, sarcoidosis, and systemic sclerosis $(\mathrm{SSc})^{52-54}$, as shown in Figure 1. However, a reduced $\mathrm{D}_{\mathrm{L}} \mathrm{CO}$ is not predictive of elevated PA pressure in COPD patients ${ }^{55}$. In patients with SSc, distinction between pulmonary arterial hypertension and ILD-associated PH may be important in determining prognosis and response to therapeutics ${ }^{56}$, and the ratio of forced vital capacity/ $\mathrm{D}_{\mathrm{L}} \mathrm{CO}$ can predict pulmonary arterial hypertension in SSc patients with mild fibrotic lung disease $^{57}$.

Assessment of exercise capacity may support a diagnosis of RV dysfunction in chronic lung disease. There is a modest negative correlation between six minute walking distance (6MWD) and estimated systolic PA pressure in COPD patients ${ }^{55}$. Significant reductions in 6MWD have been reported in IPF patients with moderate to severe $\mathrm{PH}^{58}$. Cardiopulmonary exercise testing (CPET) may be more useful in the detection of increased PA pressure in patients with chronic lung disease ${ }^{59}$. Chronic lung disease-associated increases in PVR impair the normal exercise-induced pulmonary vasodilatory response, resulting in elevated PA pressure, increased V/Q mismatch and dead space ventilation, and reduced ventilatory efficiency $\left(\mathrm{V}_{\mathrm{E}} / \mathrm{VCO}_{2}\right)$. Progressive increases in $\mathrm{V}_{\mathrm{E}} / \mathrm{VCO}_{2}$ and reductions in end-tidal $\mathrm{CO}_{2}$ measurements with exercise have been associated with secondary PH in COPD and ILD $^{60-62}$.

Elevated plasma levels of brain natriuretic peptide (BNP) or N-terminal pro-brain natriuretic peptide (NT-proBNP) are promising serological markers that may suggest RV dysfunction in chronic lung disease. Natriuretic peptides are released from cardiac myocytes in response to increased wall stress. Levels vary in populations based on age, gender, body mass index, and presence of renal dysfunction ${ }^{10}$, so they must be interpreted with caution. However, elevated BNP levels were shown to predict $\mathrm{PH}$ in patients with chronic lung disease with a reasonably high sensitivity $(85 \%)$ and specificity $(88 \%)^{63}$. In patients with COPD, BNP levels correlated with estimated PA pressure measurements even when patients were asymptomatic ${ }^{64}$.

Cardiac magnetic resonance imaging (cMRI) has been used increasingly to investigate the relationship between COPD and RV structure and function. cMRI has been used to show that concentric RV hypertrophy precedes RV dilatation in stable COPD patients without resting hypoxia ${ }^{20}$, and that exercise-induced increases in stroke volume are pre-load dependent and limited by PA pressure increases in COPD patients ${ }^{65}$. Similarly, the MESA- 
Lung study ${ }^{66}$ recently used cMRI to demonstrate that LV end-diastolic volumes and stroke volume are inversely correlated to percent emphysema, as detected by CT scan. While cMRI holds great promise in furthering our understanding of RV structure and function in chronic lung disease, expense and limited availability make the technique somewhat impractical for routine clinical use. Importantly, recent findings have shown that volumes measured by electrocardiographically-gated cardiac CT imaging are well correlated with those obtained from $\mathrm{cMRI}^{67}$, providing an additional tool for clinical use that may be more widely available.

Transthoracic echocardiography is perhaps the best initial non-invasive study to assess RV function in chronic lung disease. The technique is non-invasive and allows for serial measurements over time. Two-dimensional estimates of RV chamber size, wall thickness, PA systolic pressure, and left heart function may be useful in the evaluation of PH in patients with chronic lung disease. However, image analysis is often limited by hyperinflation or parenchymal lung abnormalities. Notably, a well-defined tricuspid regurgitant jet was present in only $20 \%$ of chronic lung disease patients in one recent study ${ }^{68}$. The correlation between estimated systolic PA pressure and pulmonary pressures measured by RHC is poor in advanced lung disease ${ }^{69}$, and estimated PA pressures are insensitive for detection of $\mathrm{PH}$ in this population. In a study of patients with advanced COPD referred for lung volume reduction surgery, echocardiographic RV systolic pressure estimates detected $\mathrm{PH}$ with a sensitivity of only $60 \%$ and specificity of $74 \%{ }^{70}$. Tricuspid annular plane systolic excursion (TAPSE) appears to be an accurate measure of RV function in PH patients, including those with PH secondary to chronic respiratory disease ${ }^{71}$. This technique is not dependent on endocardial border recognition, which can be difficult in chronic lung disease patients. Newer techniques, including three-dimension echocardiography, tissue Doppler ultrasonography, and ultrasound strain imaging may increase our abilities to non-invasively assess RV function in patients with chronic lung disease, and have been recently reviewed ${ }^{72}$.

\section{Invasive Hemodynamic Measurements}

Right heart catheterization (RHC) remains the gold-standard assessment of PH, regardless of etiology. However, the procedure is invasive, costly, and requires performance by a skilled practitioner for safety and accurate interpretation. Given the generally mild hemodynamic changes in PH associated with pulmonary disease and lack of evidence that PH-specific therapies provide benefit in this particular group (see below), RHC is not routinely recommended in this population. However, chronic lung disease patients with clinical or echocardiographic evidence of advanced RV dysfunction, out of proportion to their lung disease, might benefit from RHC, as severe PH or RV failure is usually associated with additional co-morbidities. Generally, the degree of $\mathrm{PH}$ is mild in chronic lung disease, with mean PA pressures ranging from $20-35 \mathrm{~mm} \mathrm{Hg}^{5}$. In one large retrospective review of COPD patients undergoing RHC for lung transplant evaluation, $60 \%$ of those with a mean PA pressure greater than $40 \mathrm{~mm} \mathrm{Hg}$ had some other precipitant (chronic thromboembolic disease, OSA, left ventricular disease $)^{73}$. RHC may also be indicated when considering patients for lung transplantation, as the recently developed Lung Allocation Score emphasizes the presence of $\mathrm{PH}$, particularly in ILD, thereby expediting organ allocation ${ }^{74}$.

\section{Therapeutic Options}

In general, therapies to ameliorate RV dysfunction in chronic lung disease (Table 1) are targeted at mitigating the increased PVR associated with these conditions. Long term oxygen therapy (LTOT) and therapeutics targeted at the underlying pulmonary disease constitute the basis for therapy. There is limited evidence that medications targeting the pulmonary vasculature directly have any benefit in chronic lung disease. 


\section{Long term oxygen therapy}

The survival benefit of LTOT in chronic obstructive lung disease has been recognized since the early 1980 's 16,75 . In COPD, LTOT minimizes RV afterload, as patients using supplemental oxygen for at least 15 hours daily did not develop the increased PA pressure and PVR observed in COPD patients who did not receive LTOT ${ }^{16}$. More recently, LTOT was shown to stabilize the mean PA pressure in patients with severe COPD over a 6 year course, despite progressive declines in $\mathrm{PaO}_{2}$ and $\mathrm{FEV}_{1}{ }^{76}$. LTOT minimizes acute hypoxic pulmonary vasoconstriction, and prevents further pulmonary vascular remodeling. As pulmonary hemodynamic parameters stabilize but do not improve with LTOT, it is unlikely that pulmonary vascular remodeling is reversed.

In ILD, treatment of hypoxia with LTOT is widely accepted, though not evidence based. No studies have identified a survival benefit for LTOT in ILD patients ${ }^{77}$. Supplemental oxygen therapy should be titrated carefully in ILD patients, as growing evidence supports a role for hyperoxia-mediated oxidative injury in the pathogenesis of some ILDs ${ }^{78}$. There have been no studies evaluating the effects of LTOT on pulmonary hemodynamics or RV dysfunction in patients with ILD-associated $\mathrm{PH}$.

\section{Pulmonary disease-specific therapies}

Therapies targeted at the underlying pulmonary disease are routinely recommended for treatment of Group 3 disorders, though these recommendations are not based on strong clinical evidence. Disease-specific therapies improve alveolar oxygenation, decrease V/Q mismatch, or limit the mechanical effects of hyperinflation on the pulmonary circulation.

Inhaled bronchodilators, anticholinergics, and corticosteroids remain the mainstay of therapy in obstructive lung diseases. These drugs, alone or in combination, have been shown to improve $\mathrm{FEV}_{1}$ and reduced exacerbation frequency in $\mathrm{COPD}^{79,80}$. Short-acting $\beta$-agonists and inhaled anticholinergics modestly reduced PA pressures during exercise in COPD patients, though there was no change in the $\mathrm{PVR}^{81}$. Given the associated improvements in pulmonary artery occlusion pressure with these medications, PA pressure was likely reduced through improvements in lung mechanics. Oral theophylline has been associated with improved PA pressure, PVR, and cardiac index in COPD patients ${ }^{82}$, though these effects are strongly dependent on blood levels, even within the therapeutic range ${ }^{83}$. Theophylline is used infrequently in COPD patients due to the narrow therapeutic window, and drug clearance may be reduced in patients with diminished cardiac output.

Few effective disease-specific therapies are available for ILD patients. These therapies are likely to have limited value in mitigating associated $\mathrm{PH}$, which usually develops in advanced disease when fibrotic remodeling is unlikely to respond to currently available therapies. There are limited data to suggest that corticosteroids may improve hemodynamics in diseases like sarcoidosis ${ }^{54,84}$ and pulmonary Langerhans cell histiocytosis ${ }^{85}$. These hemodynamic improvements were not routinely associated with radiographic improvements and may be related to effects on the vasculitic components of these disorders. Idiopathic pulmonary fibrosis is poorly responsive to available therapies, and current guidelines recommend against immunomodulatory pharmacotherapy in the majority of IPF patients ${ }^{86}$.

In obstructive sleep apnea, weight loss is recommended for all obese patients, and is effective at reducing the frequency of apneic episodes ${ }^{87,88}$. In patients with OHS, surgically-induced weight loss has been associated with significant improvement in pulmonary hemodynamics ${ }^{89}$. Patients with mild to moderate OSA may be treated surgically with uvulopalatopharyngoplasty (UVPP), which has been associated with a modest increase in $\mathrm{RV}$ ejection fraction ${ }^{90}$. In severe OSA, nasal continuous positive airway pressure (nCPAP) is the preferred treatment and directly improves hemodynamics. Severe OSA 
patients treated with nCPAP for 4 months demonstrated reduced resting PA pressure and PVR, and exposure to acute hypoxia caused attenuated pulmonary vasoconstriction in nCPAP-treated patients when compared to pre-treatment baselines ${ }^{91}$. While multiple potential benefits may have explained these findings (including reduction in nocturnal hypoxic episodes and improvement in cardiac function), the reduction in acute hypoxic pulmonary vasoreactivity suggests that nCPAP may improve endothelial cell function.

\section{Pulmonary hypertension-specific therapies}

Although therapies specifically designed to mitigate dysfunctional endothelial signaling and reduce pulmonary vascular tone have been used successfully to minimize the morbidity associated with pulmonary arterial hypertension, data supporting use of these medications in PH and RV dysfunction associated with chronic lung disease is less compelling. The limited available data predominantly show acute improvements in cardio-pulmonary hemodynamics, but fail to show long term functional benefits. In several cases, these medications actually worsen hypoxemia by preventing hypoxic pulmonary vasoconstriction and impair RV function by reducing venous return. Currently, these therapies are not recommended for treatment of $\mathrm{PH}$ associated with chronic lung disease ${ }^{92}$.

Inhaled nitric oxide (NO) is a pulmonary vasodilator that has been successfully used in clinical trials to improve hemodynamics and exercise capacity in patients with COPDassociated pulmonary hypertension. COPD patients who used inhaled NO, in addition to supplemental oxygen, showed significant improvements in mean PA pressure, PVR, and cardiac output ${ }^{93}$. Importantly, inhaled $\mathrm{NO}$ improved $\mathrm{V} / \mathrm{Q}$ matching and stabilized $\mathrm{PaO} 2$ during exercise in patients with $\mathrm{COPD}$-associated $\mathrm{PH}^{94}$. However, the need for continuous inhalation makes this therapy too cumbersome to be practical.

Sildenafil enhances the effects of NO on pulmonary vascular smooth muscle cells and causes pulmonary vasodilatation by inhibiting the enzyme phosphodiesterase-5 (PDE5). PDE5 is the predominant phosphodiesterase isoform in lung tissue and is responsible for catabolism of the NO second messenger cyclic guanosine monophosphate (cGMP). By inhibiting PDE5, sildenafil promotes accumulation of cGMP following NO stimulation, leading to smooth muscle cell relaxation and growth inhibition. COPD patents with pulmonary hypertension showed an acute reduction in resting and exercise-induced mean PA pressure and increased cardiac output during exercise following sildenafil administration ${ }^{95}$. Unfortunately, sildenafil was associated with a significant reduction in $\mathrm{PaO}_{2}$ due to adverse effects on V/Q matching. Long-term benefits of sildenafil in COPD patients with $\mathrm{PH}$ have not been demonstrated. Limited available data regarding the potential efficacy of PDE5 inhibitors in interstitial lung disease are conflicting. While an initial open label trial of sildenafil in IPF patients with PH showed improvements in 6MWD after 12 weeks of therapy ${ }^{96}$, a more recent randomized clinical trial failed to replicate these findings ${ }^{97}$. Patients with severe IPF treated with sildenafil reported less dyspnea and had improved $\mathrm{PaO}_{2}$ and $\mathrm{D}_{\mathrm{L}} \mathrm{CO}$ when compared to placebo, though potential effects of sildenafil on pulmonary hemodynamics were not reported ${ }^{97}$.

Endothelin 1 is produced by endothelial cells and has direct vasoconstrictor and mitogenic effects on vascular smooth muscle cells. Endothelin's vasoconstrictive effects are mediated by two receptors (ERA and ERB) on pulmonary arterial smooth muscle cells. Conversely, ERB is also functional on endothelial cells, and stimulation mediates NO production and prostacyclin release, resulting in endothelial-mediated vasodilatation. Currently available endothelin receptor antagonists target both receptors (bosentan), or selectively target ERA (sitaxsentan, ambrisentan). Bosentan has been evaluated in a randomized, controlled trial of $\mathrm{PH}$ patients with severe or very severe $\mathrm{COPD}^{98}$. The results were disappointing, as patients treated with 12 weeks of bosentan therapy showed no improvement in 6MWD or pulmonary 
hemodynamics. Bosentan-treated subjects had a reduced $\mathrm{PaO}_{2}$, a widened alveolar-arterial oxygen gradient, and reported a reduced quality of life when compared to subjects in the placebo arm $^{98}$. The selective ERA antagonist ambrisentan did not improve 6MWD in COPD or ILD patients with PH in the ARIES-3 trial ${ }^{99}$, and a phase III study of ambristentan in IPF patients with $\mathrm{PH}$ was stopped early due to lack of clinical efficacy ${ }^{39}$.

Prostacyclin, produced by endothelial cells, is a potent vasodilator, inhibits platelet aggregation, and effectively prevents the release of growth factors from endothelial cells, platelets, and macrophages. In the United States, prostacyclin analogs are available for delivery via intravenous (epoprostenol and treprostinil), subcutaneous (treprostinil), and inhaled (iloprost) routes. Acutely, intravenous prostacyclin analogs have been shown to improve mean PA pressure, PVR, and cardiac output in patients with COPD-associated pulmonary hypertension ${ }^{100}$. Unfortunately, systemically administered prostacyclin analogs have also been associated with worsened V/Q matching in COPD patients, particularly those with acute respiratory failure ${ }^{101}$, and ILD patients with $\mathrm{PH}^{102}$. There is also a theoretical risk of precipitating pulmonary edema in some ILD patients with intravenous prostacyclin analogs, as pulmonary veno-occlusive lesions have been described in several pulmonary disorders, including IPF, sarcoidosis, pulmonary Langerhans cell histiocytosis, and SScassociated ILD ${ }^{39}$.

Prostacyclin analog administration through an inhaled route may mitigate the limiting issues with V/Q mismatch and hypoxemia. COPD patients with PH were recently shown to have improved V/Q matching, a reduced alveolar-arterial oxygen gradient, and longer 6MWD after an acute treatment with inhaled iloprost ${ }^{103}$. Future studies showing sustained functional or hemodynamic effects with longer treatment courses would be encouraging.

\section{Statins}

Statins (3-hydroxy-3-methyl-glutaryl-CoA reductase inhibitors) represent an intriguing class of medications that may improve RV dysfunction associated with chronic lung disease. A recent randomized, placebo-controlled trial showed that COPD patients with $\mathrm{PH}$ who were treated with pravastatin for 6 months demonstrated a significant increase in exercise capacity, improved estimated systolic PA pressure, and reduced dyspnea scores when compared to placebo ${ }^{104}$. In a cross-sectional study of severe COPD patients undergoing right heart catheterization for lung transplant evaluation, statin use was associated with a modest reduction in mean PA pressure and pulmonary artery occlusion pressure, though there was no difference in PVR ${ }^{105}$. The mechanism by which statins may influence pulmonary hemodynamics remains unknown, though Lee et al ${ }^{104}$ showed that statin use was associated with reduced endothelin-1 production in COPD patients with PH. Interestingly, the recently completed multicenter ASA-STAT trial ${ }^{106}$ showed no improvement in 6MWD in pulmonary arterial hypertension patients taking simvastatin for 6 months, suggesting that the observed affects in COPD patients with PH may be associated with primary statin effects on the underlying lung disease or associated co-morbidities.

\section{Surgical options}

Surgical intervention is rarely warranted for the mild RV dysfunction associated with chronic lung disease. However, given the increased mortality associated with even mild PH in chronic lung disease (see below), associated PH is an indication for transplant listing based on the most recent guidelines ${ }^{107}$. In patients with PH associated with chronic lung disease, the decision between single and double lung transplantation is highly individualized, though both single and double lung transplantation have been shown to effectively reduce mean PA pressure in patients with chronic lung disease, and there appears to be no difference in long-term survival ${ }^{108}$. 
Lung volume reduction surgery (LVRS) was initially considered to be a potentially useful option to limit RV dysfunction in obstructive lung disease owing to theoretical benefits of minimizing thoracic hyperinflation. However, while LVRS was shown to improve respiratory mechanics and increase $\mathrm{PaO}_{2}$, there was no improvement in hemodynamic indices in patients undergoing LVRS compared to those treated medically ${ }^{109}$. Therefore, despite theoretical benefits, no data support routine referral for LVRS in patients with PH associated with chronic lung disease.

\section{Clinical Outcomes}

While RV remodeling and hypertrophy are relatively common in chronic lung disease, RV failure is not. Despite this, development of $\mathrm{PH}$ is uniformly associated with increased mortality in patients with chronic lung disease. In COPD, modest increases in mean PA pressure (greater than $20 \mathrm{~mm} \mathrm{Hg}$ ) have been correlated with reduced survival ${ }^{110}$. Mean PA pressure was shown to be highly predictive of long-term survival in COPD patients on LTOT, with only $36 \%$ of patients with a PA pressure greater than $25 \mathrm{~mm} \mathrm{Hg}$ surviving for 5 years compared with $62 \%$ of COPD patients with PA pressure less than $25 \mathrm{~mm} \mathrm{Hg}{ }^{111}$. Similarly, development of pulmonary hypertension has been associated with reduced survival in ILD. Patients with advanced IPF complicated by PH had a 1-year mortality of $28 \%$, while those without PH had 5.5\% 1-year mortality ${ }^{12}$. Modest increases in PA pressure are predictive of reduced long-term survival in IPF patients, as shown in Figure 2. IPF patients with a mean PA pressure greater than $17 \mathrm{~mm} \mathrm{Hg}$ had a 5 year survival of only $16.7 \%$, compared with IPF patients with a mean PA pressure less than $17 \mathrm{~mm} \mathrm{Hg}$, who had a 5 year survival of $62.2 \%{ }^{11}$. In sarcoidosis, $\mathrm{PH}$ is an independent predictor of mortality ${ }^{112}$, and the hazard ratio for death in patients with $\mathrm{PH}$ was estimated to be 10.4 when compared to patients without $\mathrm{PH}^{113}$. In patients with SSc-associated interstitial lung disease complicated by $\mathrm{PH}$, there was a five-fold increased risk of death when compared to SSc patients with $\mathrm{PAH}$, despite the notoriously poor survival in this disorder ${ }^{56}$. Data regarding mortality effects of $\mathrm{PH}$ in patients with sleep disordered breathing are a bit more challenging to interpret, primarily due to the frequent co-morbidities in this group. While the 1-, 3-, and 5-year survival estimates in OSA patients with a mean PA pressure greater than $25 \mathrm{~mm} \mathrm{Hg}$ $(93 \%, 75 \%$, and $43 \%$, respectively) were reduced when compared to those in OSA patients with normal PA pressures $(100 \%, 90 \%$, and $76 \%)$, only 31 percent of subjects with an elevated mean PA pressure had a normal pulmonary artery occlusion pressure ${ }^{114}$.

\section{Complications and Concerns}

The primary complication associated with RV dysfunction in chronic lung disease is progression to RV failure. This is a rare complication in most circumstances, though some clinical scenarios require special consideration. In COPD, acute exacerbations are associated with increased V/Q mismatch and reduced $\mathrm{PaO}_{2}{ }^{115}$. During acute exacerbations, some COPD patients develop markedly increased RV end-diastolic pressures, potentially consistent with RV failure ${ }^{116}$. Changes in RV end-diastolic pressure were associated with development of peripheral edema, $\mathrm{CO}_{2}$ retention, decreased arterial oxygen saturation, and increased mean PA pressure in that study. RV contractility was reduced in a small cohort of COPD patients evaluated by right heart catheterization following the acute development of peripheral edema ${ }^{117}$. In addition, there is a subgroup of COPD patients who appear to be at risk for development of more severe $\mathrm{PH}$ despite stable lung disease. This group accounted for $1.1 \%$ of all COPD patients undergoing hemodynamic evaluation in one large retrospective analysis ${ }^{73}$, and has a unique clinical phenotype characterized by mild to moderate airways obstruction, severely reduced $\mathrm{D}_{\mathrm{L}} \mathrm{CO}$, and severe hypoxemia. The incidence of RV failure in this subgroup is unknown. Patients with multiple chronic lung 
diseases, including overlap syndromes between COPD and OSA or ILD, may also be at increased risk for more severe RV dysfunction.

\section{Summary}

Although the exact prevalence of RV dysfunction is unknown, sufficient evidence suggests that it is a common complication of chronic pulmonary disease. The pathophysiology is characterized by mildly increased PA pressures, RV hypertrophy, and preserved RV contractility and cardiac output. However, RV dysfunction can occasionally progress to RV failure during disease exacerbations or when multiple cardio-pulmonary co-morbidities are present. Patients with severe pulmonary hypertension that is out of proportion to the underlying lung disease should be screened for these co-morbidities. The mechanism of RV dysfunction is associated primarily with hypoxic pulmonary vasoconstriction, pulmonary vascular remodeling, and disruption of pulmonary vascular beds due to the underlying lung disease. Therefore, current recommendations support the use of LTOT and pulmonary disease-specific treatments, though evidence supporting improvements in RV function is limited. Therapies designed specifically to alter pulmonary vascular tone are currently not recommended for $\mathrm{PH}$ associated with chronic lung disease, as there are limited efficacy data and multiple reports of worsening hypoxemia. Some patients with severe pulmonary hypertension, associated only with chronic lung disease and out of proportion to the underlying pulmonary disease, should be considered for enrollment in clinical trials of these or other agents. For selected patients with severe parenchymal lung disease complicated by $\mathrm{PH}$ and RV dysfunction, lung transplantation should be an early consideration.

\section{Acknowledgments}

Supported by National Heart, Lung and Blood Institute grants P50 HL084946 (P.H.) and F32 HL 110516 (T.K.)

\section{References}

1. Laennec, RT. A treatise on diseases of the chest. T. and G. Underwood; London: 1821.

2. Chronic cor pulmonale: Report of an expert committee. Circulation. 1963; 27:594-615.

3. Simonneau G, Robbins IM, Beghetti M, et al. Updated clinical classification of pulmonary hypertension. J Am Coll Cardiol. 2009; 54(1 Suppl):S43-54. [PubMed: 19555858]

4. Ben Jrad I, Slimane ML, Boujnah MR, Ben Hamda K, Ameur Y. [Prognosis and treatment of chronic cor pulmonale]. Tunis Med. 1993; 71(11):505-8. [PubMed: 8310540]

5. Weitzenblum E, Chaouat A, Canuet M, Kessler R. Pulmonary hypertension in chronic obstructive pulmonary disease and interstitial lung diseases. Semin Respir Crit Care Med. 2009; 30(4):458-70. [PubMed: 19634085]

6. Hyduk A, Croft JB, Ayala C, Zheng K, Zheng ZJ, Mensah GA. Pulmonary hypertension surveillance--United States, 1980-2002. MMWR Surveill Summ. 2005; 54(5):1-28. [PubMed: 16280974]

7. Minai OA, Chaouat A, Adnot S. Pulmonary hypertension in COPD: epidemiology, significance, and management: pulmonary vascular disease: the global perspective. Chest. 2010; 137(6 Suppl):39S51S. [PubMed: 20522579]

8. Scharf SM, Iqbal M, Keller C, Criner G, Lee S, Fessler HE. Hemodynamic characterization of patients with severe emphysema. Am J Respir Crit Care Med. 2002; 166(3):314-22. [PubMed: 12153963]

9. Badesch DB, Champion HC, Sanchez MA, et al. Diagnosis and assessment of pulmonary arterial hypertension. J Am Coll Cardiol. 2009; 54(1 Suppl):S55-66. [PubMed: 19555859]

10. Han MK, McLaughlin VV, Criner GJ, Martinez FJ. Pulmonary diseases and the heart. Circulation. 2007; 116(25):2992-3005. [PubMed: 18086941] 
11. Hamada K, Nagai S, Tanaka S, et al. Significance of pulmonary arterial pressure and diffusion capacity of the lung as prognosticator in patients with idiopathic pulmonary fibrosis. Chest. 2007; 131(3):650-56. [PubMed: 17317730]

12. Lettieri CJ, Nathan SD, Barnett SD, Ahmad S, Shorr AF. Prevalence and outcomes of pulmonary arterial hypertension in advanced idiopathic pulmonary fibrosis. Chest. 2006; 129(3):746-52. [PubMed: 16537877]

13. Nathan SD, Shlobin OA, Ahmad S, Urbanek S, Barnett SD. Pulmonary hypertension and pulmonary function testing in idiopathic pulmonary fibrosis. Chest. 2007; 131(3):657-63. [PubMed: 17356077]

14. Sajkov D, McEvoy RD. Obstructive sleep apnea and pulmonary hypertension. Prog Cardiovasc Dis. 2009; 51(5):363-70. [PubMed: 19249442]

15. Kessler R, Chaouat A, Schinkewitch P, et al. The obesity-hypoventilation syndrome revisited: a prospective study of 34 consecutive cases. Chest. 2001; 120(2):369-76. [PubMed: 11502631]

16. Long term domiciliary oxygen therapy in chronic hypoxic cor pulmonale complicating chronic bronchitis and emphysema. Report of the Medical Research Council Working Party. Lancet. 1981; 1(8222):681-86. [PubMed: 6110912]

17. Bogaard HJ, Abe K, Vonk Noordegraaf A, Voelkel NF. The right ventricle under pressure: cellular and molecular mechanisms of right-heart failure in pulmonary hypertension. Chest. 2009; 135(3): 794-804. [PubMed: 19265089]

18. Kayar SR, Banchero N. Myocardial capillarity in acclimation to hypoxia. Pflugers Arch. 1985; 404(4):319-25. [PubMed: 4059024]

19. Partovian C, Adnot S, Eddahibi S, et al. Heart and lung VEGF mRNA expression in rats with monocrotaline- or hypoxia-induced pulmonary hypertension. Am J Physiol. 1998; 275(6):H194856. [PubMed: 9843792]

20. Vonk-Noordegraaf A, Marcus JT, Holverda S, Roseboom B, Postmus PE. Early changes of cardiac structure and function in COPD patients with mild hypoxemia. Chest. 2005; 127(6):1898-1903. [PubMed: 15947300]

21. Scott KW. A clinicopathological study of fatal chronic airways obstruction. Thorax. 1976; 31(6): 693-701. [PubMed: 138210]

22. Shivkumar K, Ravi K, Henry JW, Eichenhorn M, Stein PD. Right ventricular dilatation, right ventricular wall thickening, and Doppler evidence of pulmonary hypertension in patients with a pure restrictive ventilatory impairment. Chest. 1994; 106(6):1649-53. [PubMed: 7988179]

23. Bradley TD, Rutherford R, Grossman RF, et al. Role of daytime hypoxemia in the pathogenesis of right heart failure in the obstructive sleep apnea syndrome. Am Rev Respir Dis. 1985; 131(6):83539. [PubMed: 4003933]

24. Guidry UC, Mendes LA, Evans JC, et al. Echocardiographic features of the right heart in sleepdisordered breathing: the Framingham Heart Study. Am J Respir Crit Care Med. 2001; 164(6): 933-38. [PubMed: 11587973]

25. Dursunoglu N, Dursunoglu D, Kilic M. Impact of obstructive sleep apnea on right ventricular global function: sleep apnea and myocardial performance index. Respiration. 2005; 72(3):278-84. [PubMed: 15942297]

26. Vizza CD, Lynch JP, Ochoa LL, Richardson G, Trulock EP. Right and left ventricular dysfunction in patients with severe pulmonary disease. Chest. 1998; 113(3):576-83. [PubMed: 9515827]

27. Burghuber OC, Bergmann H. Right-ventricular contractility in chronic obstructive pulmonary disease: a combined radionuclide and hemodynamic study. Respiration. 1988; 53(1):1-12. [PubMed: 3387685]

28. Biernacki W, Flenley DC, Muir AL, MacNee W. Pulmonary hypertension and right ventricular function in patients with COPD. Chest. 1988; 94(6):1169-75. [PubMed: 3191757]

29. Caso P, Galderisi M, Cicala S, et al. Association between myocardial right ventricular relaxation time and pulmonary arterial pressure in chronic obstructive lung disease: analysis by pulsed Doppler tissue imaging. J Am Soc Echocardiogr. 2001; 14(10):970-77. [PubMed: 11593201]

30. Huez S, Retailleau K, Unger P, et al. Right and left ventricular adaptation to hypoxia: a tissue Doppler imaging study. Am J Physiol Heart Circ Physiol. 2005; 289(4):H1391-98. [PubMed: 15923316] 
31. Archer S, Michelakis E. The mechanism(s) of hypoxic pulmonary vasoconstriction: potassium channels, redox $\mathrm{O}(2)$ sensors, and controversies. News Physiol Sci. 2002; 17:131-37. [PubMed: 12136039]

32. Enson Y, Giuntini C, Lewis ML, Morris TQ, Ferrer MI, Harvey RM. The Influence of Hydrogen Ion Concentration and Hypoxia on the Pulmonary Circulation. J Clin Invest. 1964; 43:1146-62. [PubMed: 14171792]

33. Timms RM, Khaja FU, Williams GW. Hemodynamic response to oxygen therapy in chronic obstructive pulmonary disease. Ann Intern Med. 1985; 102(1):29-36. [PubMed: 3966742]

34. Girgis RE, Mathai SC. Pulmonary hypertension associated with chronic respiratory disease. Clin Chest Med. 2007; 28(1):219-32. [PubMed: 17338937]

35. Wilkinson M, Langhorne CA, Heath D, Barer GR, Howard P. A pathophysiological study of 10 cases of hypoxic cor pulmonale. Q J Med. 1988; 66(249):65-85. [PubMed: 3174923]

36. Penaloza D, Arias-Stella J. The heart and pulmonary circulation at high altitudes: healthy highlanders and chronic mountain sickness. Circulation. 2007; 115(9):1132-46. [PubMed: 17339571]

37. Matsuoka S, Washko GR, Yamashiro T, et al. Pulmonary hypertension and computed tomography measurement of small pulmonary vessels in severe emphysema. Am J Respir Crit Care Med. 2010; 181(3):218-25. [PubMed: 19875683]

38. Falk JA, Martin UJ, Scharf S, Criner GJ. Lung elastic recoil does not correlate with pulmonary hemodynamics in severe emphysema. Chest. 2007; 132(5):1476-84. [PubMed: 17908710]

39. Shlobin OA, Nathan SD. Pulmonary hypertension secondary to interstitial lung disease. Expert Rev Respir Med. 2011; 5(2):179-89. [PubMed: 21510729]

40. Nathan SD, Noble PW, Tuder RM. Idiopathic pulmonary fibrosis and pulmonary hypertension: connecting the dots. Am J Respir Crit Care Med. 2007; 175(9):875-80. [PubMed: 17255562]

41. Tillie-Leblond I, Marquette $\mathrm{CH}$, Perez T, et al. Pulmonary embolism in patients with unexplained exacerbation of chronic obstructive pulmonary disease: prevalence and risk factors. Ann Intern Med. 2006; 144(6):390-96. [PubMed: 16549851]

42. Rizkallah J, Man SF, Sin DD. Prevalence of pulmonary embolism in acute exacerbations of COPD: a systematic review and metaanalysis. Chest. 2009; 135(3):786-93. [PubMed: 18812453]

43. Swigris JJ, Olson AL, Huie TJ, et al. Increased risk of pulmonary embolism among US decedents with sarcoidosis from 1988 to 2007. Chest. 2011; 140(5):1261-66. [PubMed: 21565969]

44. Panos RJ, Mortenson RL, Niccoli SA, King TE Jr. Clinical deterioration in patients with idiopathic pulmonary fibrosis: causes and assessment. Am J Med. 1990; 88(4):396-404. [PubMed: 2183601]

45. Fessler HE. Heart-lung interactions: applications in the critically ill. Eur Respir J. 1997; 10(1):22637. [PubMed: 9032519]

46. Watz H, Waschki B, Meyer T, et al. Decreasing cardiac chamber sizes and associated heart dysfunction in COPD: role of hyperinflation. Chest. 2010; 138(1):32-8. [PubMed: 20190002]

47. Buda AJ, Pinsky MR, Ingels NB Jr. Daughters GT 2nd, Stinson EB, Alderman EL. Effect of intrathoracic pressure on left ventricular performance. N Engl J Med. 1979; 301(9):453-59. [PubMed: 460363]

48. Macnee W. Right heart function in COPD. Semin Respir Crit Care Med. 2010; 31(3):295-312. [PubMed: 20496299]

49. Oswald-Mammosser M, Oswald T, Nyankiye E, Dickele MC, Grange D, Weitzenblum E. Noninvasive diagnosis of pulmonary hypertension in chronic obstructive pulmonary disease.

Comparison of ECG, radiological measurements, echocardiography and myocardial scintigraphy. Eur J Respir Dis. 1987; 71(5):419-29. [PubMed: 3443164]

50. Tan RT, Kuzo R, Goodman LR, Siegel R, Haasler GB, Presberg KW. Utility of CT scan evaluation for predicting pulmonary hypertension in patients with parenchymal lung disease. Medical College of Wisconsin Lung Transplant Group. Chest. 1998; 113(5):1250-56. [PubMed: 9596302]

51. Zisman DA, Karlamangla AS, Ross DJ, et al. High-resolution chest CT findings do not predict the presence of pulmonary hypertension in advanced idiopathic pulmonary fibrosis. Chest. 2007; 132(3):773-79. [PubMed: 17573485]

52. Steen VD, Graham G, Conte C, Owens G, Medsger TA Jr. Isolated diffusing capacity reduction in systemic sclerosis. Arthritis Rheum. 1992; 35(7):765-70. [PubMed: 1622414] 
53. Nadrous HF, Pellikka PA, Krowka MJ, et al. Pulmonary hypertension in patients with idiopathic pulmonary fibrosis. Chest. 2005; 128(4):2393-99. [PubMed: 16236900]

54. Nunes H, Humbert M, Capron F, et al. Pulmonary hypertension associated with sarcoidosis: mechanisms, haemodynamics and prognosis. Thorax. 2006; 61(1):68-74. [PubMed: 16227329]

55. Gartman EJ, Blundin M, Klinger JR, Yammine J, Roberts MB, McCool F Dennis. Initial Risk Assessment for Pulmonary Hypertension in Patients with COPD. Lung. Published online Nov 18 2011.

56. Mathai SC, Hummers LK, Champion HC, et al. Survival in pulmonary hypertension associated with the scleroderma spectrum of diseases: impact of interstitial lung disease. Arthritis Rheum. 2009; 60(2):569-77. [PubMed: 19180517]

57. Steen V, Medsger TA Jr. Predictors of isolated pulmonary hypertension in patients with systemic sclerosis and limited cutaneous involvement. Arthritis Rheum. 2003; 48(2):516-22. [PubMed: 12571862]

58. Leuchte HH, Neurohr C, Baumgartner R, et al. Brain natriuretic peptide and exercise capacity in lung fibrosis and pulmonary hypertension. Am J Respir Crit Care Med. 2004; 170(4):360-65. [PubMed: 15087298]

59. Arena R, Guazzi M, Myers J, Grinnen D, Forman DE, Lavie CJ. Cardiopulmonary exercise testing in the assessment of pulmonary hypertension. Expert Rev Respir Med. 2011; 5(2):281-93. [PubMed: 21510737]

60. Holverda S, Bogaard HJ, Groepenhoff H, Postmus PE, Boonstra A, Vonk-Noordegraaf A. Cardiopulmonary exercise test characteristics in patients with chronic obstructive pulmonary disease and associated pulmonary hypertension. Respiration. 2008; 76(2):160-67. [PubMed: 17960052]

61. Vonbank K, Funk GC, Marzluf B, et al. Abnormal pulmonary arterial pressure limits exercise capacity in patients with COPD. Wien Klin Wochenschr. 2008; 120(23-24):749-55. [PubMed: 19122986]

62. Glaser S, Noga O, Koch B, et al. Impact of pulmonary hypertension on gas exchange and exercise capacity in patients with pulmonary fibrosis. Respir Med. 2009; 103(2):317-24. [PubMed: 18804360]

63. Leuchte HH, Baumgartner RA, Nounou ME, et al. Brain natriuretic peptide is a prognostic parameter in chronic lung disease. Am J Respir Crit Care Med. 2006; 173(7):744-50. [PubMed: 16415273]

64. Inoue Y, Kawayama T, Iwanaga T, Aizawa H. High plasma brain natriuretic peptide levels in stable COPD without pulmonary hypertension or cor pulmonale. Intern Med. 2009; 48(7):503-12. [PubMed: 19336951]

65. Holverda S, Rietema H, Westerhof N, et al. Stroke volume increase to exercise in chronic obstructive pulmonary disease is limited by increased pulmonary artery pressure. Heart. 2009; 95(2):137-41. [PubMed: 18474537]

66. Barr RG, Bluemke DA, Ahmed FS, et al. Percent emphysema, airflow obstruction, and impaired left ventricular filling. N Engl J Med. 2010; 362(3):217-27. [PubMed: 20089972]

67. Gao Y, Du X, Liang L, Cao L, Yang Q, Li K. Evaluation of right ventricular function by 64-row $\mathrm{CT}$ in patients with chronic obstructive pulmonary disease and cor pulmonale. Eur J Radiol. Published online Nov 262010.

68. Burgess MI, Bright-Thomas R. Usefulness of transcutaneous Doppler jugular venous echo to predict pulmonary hypertension in COPD patients. Eur Respir J. 2002; 19(2):382-83. [PubMed: $11866021]$

69. Arcasoy SM, Christie JD, Ferrari VA, et al. Echocardiographic assessment of pulmonary hypertension in patients with advanced lung disease. Am J Respir Crit Care Med. 2003; 167(5): 735-40. [PubMed: 12480614]

70. Fisher MR, Criner GJ, Fishman AP, et al. Estimating pulmonary artery pressures by echocardiography in patients with emphysema. Eur Respir J. 2007; 30(5):914-21. [PubMed: 17652313] 
71. Forfia PR, Fisher MR, Mathai SC, et al. Tricuspid annular displacement predicts survival in pulmonary hypertension. Am J Respir Crit Care Med. 2006; 174(9):1034-41. [PubMed: 16888289]

72. Mertens LL, Friedberg MK. Imaging the right ventricle--current state of the art. Nat Rev Cardiol. 2010; 7(10):551-63. [PubMed: 20697412]

73. Chaouat A, Bugnet AS, Kadaoui N, et al. Severe pulmonary hypertension and chronic obstructive pulmonary disease. Am J Respir Crit Care Med. 2005; 172(2):189-94. [PubMed: 15831842]

74. Egan TM, Murray S, Bustami RT, et al. Development of the new lung allocation system in the United States. Am J Transplant. 2006; 6(5 Pt 2):1212-27. [PubMed: 16613597]

75. Continuous or nocturnal oxygen therapy in hypoxemic chronic obstructive lung disease: a clinical trial. Nocturnal Oxygen Therapy Trial Group. Ann Intern Med. 1980; 93(3):391-98. [PubMed: 6776858]

76. Zielinski J, Tobiasz M, Hawrylkiewicz I, Sliwinski P, Palasiewicz G. Effects of long-term oxygen therapy on pulmonary hemodynamics in COPD patients: a 6-year prospective study. Chest. 1998; 113(1):65-70. [PubMed: 9440570]

77. Crockett AJ, Cranston JM, Antic N. Domiciliary oxygen for interstitial lung disease. Cochrane Database Syst Rev. 2001; (3) CD002883.

78. Kliment CR, Oury TD. Oxidative stress, extracellular matrix targets, and idiopathic pulmonary fibrosis. Free Radic Biol Med. 2010; 49(5):707-17. [PubMed: 20452419]

79. Calverley PM, Anderson JA, Celli B, et al. Salmeterol and fluticasone propionate and survival in chronic obstructive pulmonary disease. N Engl J Med. 2007; 356(8):775-89. [PubMed: 17314337]

80. Tashkin DP, Celli B, Senn S, et al. A 4-year trial of tiotropium in chronic obstructive pulmonary disease. N Engl J Med. 2008; 359(15):1543-54. [PubMed: 18836213]

81. Saito S, Miyamoto K, Nishimura M, et al. Effects of inhaled bronchodilators on pulmonary hemodynamics at rest and during exercise in patients with COPD. Chest. 1999; 115(2):376-82. [PubMed: 10027435]

82. Matthay RA. Favorable cardiovascular effects of theophylline in COPD. Chest. 1987; 92(1 Suppl): 22S-26S. [PubMed: 3297523]

83. Mols P, Huynh CH, Dechamps P, Naeije N, Ham HR. Dose dependency of aminophylline effects on hemodynamic and ventricular function in patients with chronic obstructive pulmonary disease. Chest. 1993; 103(6):1725-31. [PubMed: 8404091]

84. Gluskowski J, Hawrylkiewicz I, Zych D, Zielinski J. Effects of corticosteroid treatment on pulmonary haemodynamics in patients with sarcoidosis. Eur Respir J. 1990; 3(4):403-7. [PubMed: 2365034]

85. Benyounes B, Crestani B, Couvelard A, Vissuzaine C, Aubier M. Steroid-responsive pulmonary hypertension in a patient with Langerhans' cell granulomatosis (histiocytosis X). Chest. 1996; 110(1):284-86. [PubMed: 8681645]

86. Raghu G, Collard HR, Egan JJ, et al. An official ATS/ERS/JRS/ALAT statement: idiopathic pulmonary fibrosis: evidence-based guidelines for diagnosis and management. Am J Respir Crit Care Med. 2011; 183(6):788-824. [PubMed: 21471066]

87. Grunstein RR, Stenlof K, Hedner JA, Peltonen M, Karason K, Sjostrom L. Two year reduction in sleep apnea symptoms and associated diabetes incidence after weight loss in severe obesity. Sleep. 2007; 30(6):703-10. [PubMed: 17580591]

88. Johansson K, Neovius M, Lagerros YT, et al. Effect of a very low energy diet on moderate and severe obstructive sleep apnoea in obese men: a randomised controlled trial. BMJ. 2009; 339:b4609. [PubMed: 19959590]

89. Sugerman HJ, Baron PL, Fairman RP, Evans CR, Vetrovec GW. Hemodynamic dysfunction in obesity hypoventilation syndrome and the effects of treatment with surgically induced weight loss. Ann Surg. 1988; 207(5):604-13. [PubMed: 3377570]

90. Zohar Y, Talmi YP, Frenkel H, et al. Cardiac function in obstructive sleep apnea patients following uvulopalatopharyngoplasty. Otolaryngol Head Neck Surg. 1992; 107(3):390-94. [PubMed: 1383911] 
91. Sajkov D, Wang T, Saunders NA, Bune AJ, McEvoy RD. Continuous positive airway pressure treatment improves pulmonary hemodynamics in patients with obstructive sleep apnea. Am J Respir Crit Care Med. 2002; 165(2):152-58. [PubMed: 11790646]

92. Hoeper MM, Barbera JA, Channick RN, et al. Diagnosis, assessment, and treatment of nonpulmonary arterial hypertension pulmonary hypertension. J Am Coll Cardiol. 2009; 54(1 Suppl):S85-96. [PubMed: 19555862]

93. Vonbank K, Ziesche R, Higenbottam TW, et al. Controlled prospective randomised trial on the effects on pulmonary haemodynamics of the ambulatory long term use of nitric oxide and oxygen in patients with severe COPD. Thorax. 2003; 58(4):289-93. [PubMed: 12668787]

94. Roger N, Barbera JA, Roca J, Rovira I, Gomez FP, Rodriguez-Roisin R. Nitric oxide inhalation during exercise in chronic obstructive pulmonary disease. Am J Respir Crit Care Med. 1997; 156(3 Pt 1):800-6. [PubMed: 9309996]

95. Blanco I, Gimeno E, Munoz PA, et al. Hemodynamic and gas exchange effects of sildenafil in patients with chronic obstructive pulmonary disease and pulmonary hypertension. Am J Respir Crit Care Med. 2010; 181(3):270-78. [PubMed: 19875684]

96. Collard HR, Anstrom KJ, Schwarz MI, Zisman DA. Sildenafil improves walk distance in idiopathic pulmonary fibrosis. Chest. 2007; 131(3):897-99. [PubMed: 17356110]

97. Zisman DA, Schwarz M, Anstrom KJ, Collard HR, Flaherty KR, Hunninghake GW. A controlled trial of sildenafil in advanced idiopathic pulmonary fibrosis. N Engl J Med. 2010; 363(7):620-28. [PubMed: 20484178]

98. Stolz D, Rasch H, Linka A, et al. A randomised, controlled trial of bosentan in severe COPD. Eur Respir J. 2008; 32(3):619-28. [PubMed: 18448495]

99. Badesch DB, Feldman J, Keogh A, et al. ARIES-3: Ambrisentan Therapy in a Diverse Population of Patients with Pulmonary Hypertension. Cardiovasc Ther. Published online Jun 202011.

100. Naeije R, Melot C, Mols P, Hallemans R. Reduction in pulmonary hypertension by prostaglandin E1 in decompensated chronic obstructive pulmonary disease. Am Rev Respir Dis. 1982; 125(1): 1-5. [PubMed: 6802045]

101. Archer SL, Mike D, Crow J, Long W, Weir EK. A placebo-controlled trial of prostacyclin in acute respiratory failure in COPD. Chest. 1996; 109(3):750-55. [PubMed: 8617086]

102. Ghofrani HA, Wiedemann R, Rose F, et al. Sildenafil for treatment of lung fibrosis and pulmonary hypertension: a randomised controlled trial. Lancet. 2002; 360(9337):895-900. [PubMed: 12354470]

103. Dernaika TA, Beavin M, Kinasewitz GT. Iloprost improves gas exchange and exercise tolerance in patients with pulmonary hypertension and chronic obstructive pulmonary disease. Respiration. 2010; 79(5):377-82. [PubMed: 19786728]

104. Lee TM, Chen CC, Shen HN, Chang NC. Effects of pravastatin on functional capacity in patients with chronic obstructive pulmonary disease and pulmonary hypertension. Clin Sci (Lond). 2009; 116(6):497-505. [PubMed: 18831711]

105. Reed RM, Iacono A, DeFilippis A, et al. Statin therapy is associated with decreased pulmonary vascular pressures in severe COPD. COPD. 2011; 8(2):96-102. [PubMed: 21495837]

106. Kawut SM, Bagiella E, Lederer DJ, et al. Randomized clinical trial of aspirin and simvastatin for pulmonary arterial hypertension: ASA-STAT. Circulation. 2011; 123(25):2985-93. [PubMed: 21593252]

107. Orens JB, Estenne M, Arcasoy S, et al. International guidelines for the selection of lung transplant candidates: 2006 update--a consensus report from the Pulmonary Scientific Council of the International Society for Heart and Lung Transplantation. J Heart Lung Transplant. 2006; 25(7): 745-55. [PubMed: 16818116]

108. Fitton TP, Kosowski TR, Barreiro CJ, et al. Impact of secondary pulmonary hypertension on lung transplant outcome. J Heart Lung Transplant. 2005; 24(9):1254-59. [PubMed: 16143242]

109. Criner GJ, Scharf SM, Falk JA, et al. Effect of lung volume reduction surgery on resting pulmonary hemodynamics in severe emphysema. Am J Respir Crit Care Med. 2007; 176(3):25360. [PubMed: 17496227] 
110. Weitzenblum E, Hirth C, Ducolone A, Mirhom R, Rasaholinjanahary J, Ehrhart M. Prognostic value of pulmonary artery pressure in chronic obstructive pulmonary disease. Thorax. 1981; 36(10):752-58. [PubMed: 7330793]

111. Oswald-Mammosser M, Weitzenblum E, Quoix E, et al. Prognostic factors in COPD patients receiving long-term oxygen therapy. Importance of pulmonary artery pressure. Chest. 1995; 107(5):1193-98. [PubMed: 7750305]

112. Shorr AF, Davies DB, Nathan SD. Predicting mortality in patients with sarcoidosis awaiting lung transplantation. Chest. 2003; 124(3):922-28. [PubMed: 12970018]

113. Baughman RP, Engel PJ, Taylor L, Lower EE. Survival in sarcoidosis-associated pulmonary hypertension: the importance of hemodynamic evaluation. Chest. 2010; 138(5):1078-85. [PubMed: 20348196]

114. Minai OA, Ricaurte B, Kaw R, et al. Frequency and impact of pulmonary hypertension in patients with obstructive sleep apnea syndrome. Am J Cardiol. 2009; 104(9):1300-6. [PubMed: 19840581]

115. Barbera JA, Roca J, Ferrer A, et al. Mechanisms of worsening gas exchange during acute exacerbations of chronic obstructive pulmonary disease. Eur Respir J. 1997; 10(6):1285-91. [PubMed: 9192930]

116. Weitzenblum E, Apprill M, Oswald M, Chaouat A, Imbs JL. Pulmonary hemodynamics in patients with chronic obstructive pulmonary disease before and during an episode of peripheral edema. Chest. 1994; 105(5):1377-182. [PubMed: 8181323]

117. MacNee W, Wathen CG, Flenley DC, Muir AD. The effects of controlled oxygen therapy on ventricular function in patients with stable and decompensated cor pulmonale. Am Rev Respir Dis. 1988; 137(6):1289-95. [PubMed: 3202369] 


\section{Box 1}

\section{Key Points}

- The prevalence of pulmonary hypertension and right ventricular remodeling is variable in chronic lung disease but increases with disease progression.

- Chronic hypoxemia and disruption of pulmonary vascular beds contribute to increase pulmonary vascular resistance and promote right ventricular remodeling.

- Right ventricular contractility is generally preserved in chronic lung disease.

- Right ventricular dysfunction can be difficult to distinguish non-invasively from underlying progression of pulmonary disease.

- Correction of hypoxia with long term oxygen therapy and pulmonary diseasespecific therapies are the mainstay of treatment.

- Pulmonary hypertension-specific therapies have not shown benefit in right ventricular dysfunction associated with chronic lung disease and may worsen hypoxia.

- Development of pulmonary hypertension and right ventricular dysfunction worsens survival in chronic lung disease.

- Right ventricular failure is rare except during acute exacerbations of chronic lung disease or when multiple co-morbidities are present. 


\section{Box 2}

\section{Chronic lung diseases associated with pulmonary hypertension and right} ventricular dysfunction

- Chronic obstructive pulmonary disease

- Interstitial lung disease

- Mixed obstructive and restrictive lung disease

- $\quad$ Sleep-disordered breathing

- Alveolar hypoventilation disorders

- Chronic exposure to high altitude

- Developmental abnormalities 

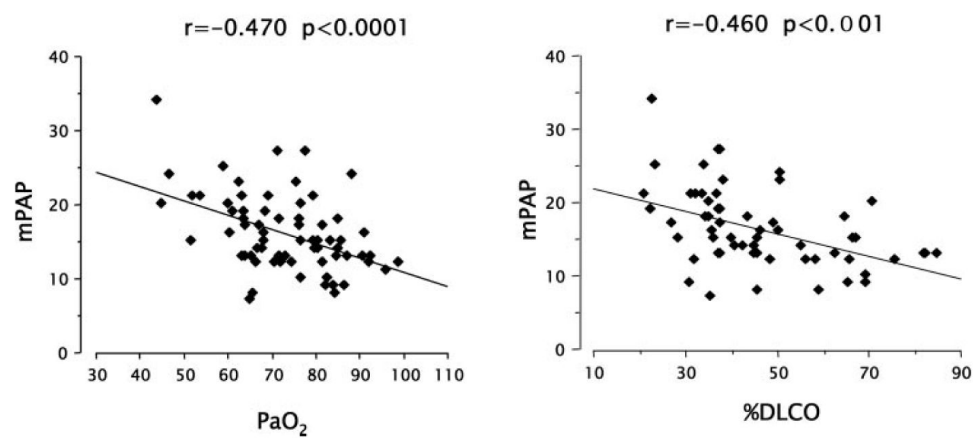

Figure 1.

Correlation of mean pulmonary arterial pressure (mPAP) with $\mathrm{PaO} 2$ (left and percentage of predicted $\mathrm{D}_{\mathrm{L}} \mathrm{CO}\left(\% \mathrm{D}_{\mathrm{L}} \mathrm{CO}\right.$; right) in patients with idiopathic pulmonary fibrosis. From Hamada K, Nagai S, Tanaka S, et al. Significance of pulmonary arterial pressure and diffusion capacity of the lung as prognosticator in patients with idiopathic pulmonary fibrosis. Chest. 2007; 131(3):650-56, with permission. 


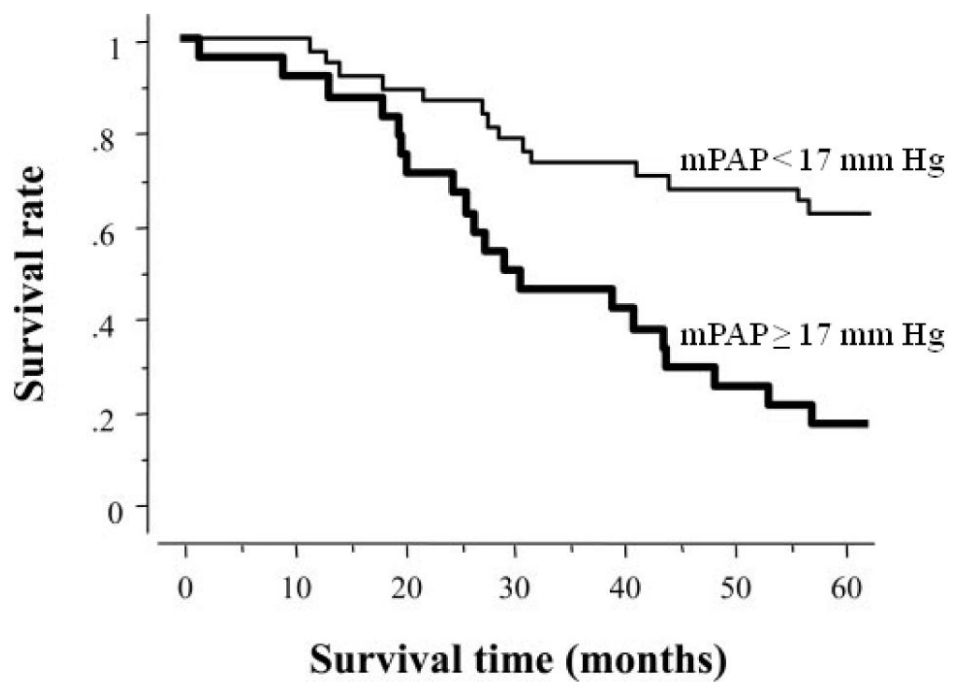

Figure 2.

Prognostic impact of mean pulmonary arterial pressure (mPAP) on survival in patients with idiopathic pulmonary fibrosis (IPF). Thin line represents IPF patients with normal mPAP $(n=37)$; thick line represents IPF patients with elevated mPAP $(n=24)$. Adapted from Hamada K, Nagai S, Tanaka S, et al. Significance of pulmonary arterial pressure and diffusion capacity of the lung as prognosticator in patients with idiopathic pulmonary fibrosis. Chest. 2007; 131(3):650-56, with permission. 
(Table 1)

Therapeutic options for right ventricular dysfunction in chronic pulmonary disease

\begin{tabular}{|c|c|}
\hline Therapy & Likely to Benefit \\
\hline Long-term oxygen therapy & $\begin{array}{l}\text { All patients with resting, ambulatory, or } \\
\text { nocturnal hypoxemia }\end{array}$ \\
\hline Diuretics & All patients with peripheral edema \\
\hline \multicolumn{2}{|l|}{ Disease-specific therapy } \\
\hline Smoking cessation & All patients \\
\hline Pulmonary rehabilitation & $\begin{array}{l}\text { All patients with advanced obstructive or } \\
\text { restrictive lung disease }\end{array}$ \\
\hline $\begin{array}{l}\text { Inhaled bronchodilators, } \\
\text { anticholinergics, and corticosteroids }\end{array}$ & $\begin{array}{l}\text { Chronic obstructive pulmonary disease, } \\
\text { asthma, other obstructive lung disease }\end{array}$ \\
\hline $\begin{array}{l}\text { Systemic corticosteroids } \\
\text { and other immunosuppressants }\end{array}$ & $\begin{array}{l}\text { Unknown, potential benefit in sarcoidosis, } \\
\text { pulmonary Langerhans cell histiocytosis }\end{array}$ \\
\hline Weight loss & All patients with obesity \\
\hline Uvulopalatopharyngoplasty & Patients with mild to moderate OSA \\
\hline Nasal CPAP & All patients with sleep-disordered breathing \\
\hline \multicolumn{2}{|l|}{ Pulmonary hypertension-specific therapy } \\
\hline Inhaled nitric oxide & Chronic obstructive pulmonary disease \\
\hline Phosphodiesterase-5 inhibitors & Unknown \\
\hline Endothelin receptor antagonists & Unknown \\
\hline Prostacyclin analogs & $\begin{array}{l}\text { Unknown; may be some benefit with inhaled } \\
\text { formulation in COPD }\end{array}$ \\
\hline Statins & Unknown \\
\hline \multicolumn{2}{|l|}{ Surgical options } \\
\hline Lung volume reduction surgery & None \\
\hline Lung transplantation & $\begin{array}{l}\text { Selected patients with severe parenchymal } \\
\text { lung disease complicated by } \mathrm{PH}\end{array}$ \\
\hline
\end{tabular}

